\title{
The First Evidence of Familial Lung Cancer in Latvia by Population Screening for Hereditary Cancer
}

\author{
Andrejs Vanags, Jelena Grushina, Ilze Strumfa, Janis Gardovskis \\ Hereditary Cancer Institute, Riga Stradins University, Latvia
}

\begin{abstract}
Summary
Introduction. Lung cancer is the major worldwide cause of tumour lethality. Recently, the role of heredity in lung carcinogenesis has become an important scientific target. While there is ongoing search for the respective gene mutations, it was suggested that presence of at least 2 first-degree relatives with lung cancer should reveal the familial lung cancer.

Aim of the study. We present the first documented evidence of familial lung cancer in Latvia by population screening data in order to improve the planning of early cancer diagnostics. Materials and methods. The investigation was designed as population screening for hereditary cancer. Family cancer history was obtained from 18642 adults in the Valka district $(76.6 \%$ of the adult population). Data analysis and proband consultations were performed in Hereditary Cancer Institute. Hereditary cancer syndromes were diagnosed by clinical criteria.

Results. Familial lung cancer syndrome was diagnosed in 13 probands, but suspected familial lung cancer syndrome (sFLC) - in 93 probands, corresponding to the frequency $0.6 \%(95 \%$ confidence interval $(\mathrm{Cl})=0.5-0.7 \%)$. The frequency of lung cancer among blood relatives was $25.5 \%(95 \% \mathrm{Cl}=19.3-32.8 \%)$ in definitive and $17.2 \%(95 \% \mathrm{Cl}=15.0-19.7 \%)$ in suspected syndrome groups exceeding significantly the cumulative risk for EU population. Number of affected generations was significant for sFLC. The age of cancer onset did not influence the frequency of cancer. The data about the cancer course are described. Conclusions. The high frequency of lung cancer in the identified pedigrees supports the role of familial factors in the lung carcinogenesis as well as the practical value of our diagnostic criteria helping to identify high-risk group for intervention measures to prevent lung cancer.
\end{abstract}

Key words: familial lung cancer, population screening.

\section{INTRODUCTION}

Lung cancer is the most common cancer in the world (Parkin et al., 2005) and the leading cause of cancer death in Europe (Boyle and Ferlay, 2005) and the whole world (Nitadori et al., 2006) due to its frequent occurrence and grave prognosis implying 5-year-survival of $15 \%$ in the case of best available treatment. Tobacco smoking is the main risk factor for lung cancer causing approximately $90 \%$ of the lung cancer cases. Lot of scientific efforts has been applied to the analysis of tobacco-initiated lung carcinogenesis. Diminishing of the smoking frequency in the population is an effective measure in lung cancer prevention causing concentration of organizational and informative efforts in this direction. Thus, studies of the hereditary factors in lung cancer run behind similar research concerning tumours in other locations although the first records suggesting the familial clustering of lung cancer date back to the middle of the previous century (Tokuhata et al., 1963).

Up to 2005, 31 case-control studies and 17 cohort studies were published on this field (Matakidou, Eisen and Houlston, 2005). Multivariate analysis of the family history of women with lung cancer showed that presence of lung cancer in a first-degree relative significantly increases the frequency of lung cancer with odds ratio (OR) 1.61 (Rachtan et al., 2008). Similar results were obtained in the United Kingdom by Matakidou et al., 2005: the frequency of lung cancer in female was increased if a first-degree relative was affected by lung cancer (OR,
$1.49 ; 95 \% \mathrm{CI}=1.13-1.96)$ and was further increased having higher numbers of affected relatives (OR, 2.68, $95 \%$ CI $=1.29-5.55)$. A large-scale population-based prospective cohort study, conducted in Japan over time period of 13 years, confirmed that frequency of lung cancer was higher in persons who had family history of lung cancer in first-degree relative (Nitadori et al., 2006). In Iceland, increased relative risks for the kinship of lung cancer patients were demonstrated by Jonsson et al., 2004.

Controversial data are published about the possible link between familial nature and histologic type of lung cancer. Squamous cell cancer had the strongest association with family history in several studies (Nitadori et al., 2006; Ambrosone et al., 1993). Statistically insignificant trend to the highest family-size-adjusted mean number of lung cancer cases per family was found for small cell cancer (Sellers et al., 1992). The data from the Swedish Family - Cancer Database and Swedish Cancer Registry, used to compare the lung cancer frequency in persons with parental family history to those without positive family history, indicated that the frequency was highest for adenocarcinoma (Li and Hemminki, 2003). Adenocarcinoma showed stronger association with familial background among non-smoking USA females (Wu et al., 1996). No association was found by Ganti et al., 2009.

Although few data are available, positive family history has been associated with a trend towards slightly lower 
survival in lung cancer patients (Ganti et al, 2009). The survival from lung cancer correlated between blood relatives but not in spouses (Lindström et al., 2009). The development of second lung cancer may be stronger influenced by genetic factors (Li and Hemminki, 2005). There are different hypotheses about the mode of lung cancer inheritance. Highly penetrant recessive gene was suspected by Hemminki and Li, 2005 who found higher risk in siblings than in the offspring of lung cancer patients (2.15 and 1.77, respectively). The autosomal dominant inheritance implying rare gene was suggested by segregation analysis (Sellers et al., 1990). By finding no clinical evidence of link between Li-Fraumeni syndrome, familial retinoblastoma, familial melanoma and families with aggregation of lung cancer it was concluded that mutations of p53, Rb, pl6 and mismatch repair genes although frequent in somatic lung cancer play no significant hereditary role in lung cancer (Tomizawa et al., 1998).

The possible genetic loci of familial lung cancer susceptibility are described in chromosome 6q23-25 (You et al., 2009; Bailey-Wilson et al., 2004), 15q2425.1 (Liu et al., 2008) and chromosome 12 (Schwartz and Ruckdeschel, 2006). Significant association has been found between lung cancer susceptibility and 3 single nucleotide polymorphisms in the first intron of the RGS17 gene. Accumulation of the transcripts of this gene was shown in lung cancer tissues (You et al., 2009). A family with multiple cases of non-small cell lung cancer and germline mutation of the T790M is reported (Bell et al., 2005).

The initially mapped susceptibility locus 6q23-25 corresponds to genomic region that is deleted not only in lung cancers but in other malignancies (Bailey-Wilson et al., 2004). By family history analysis of Japanese lung cancer patients in the setting of multiple primary malignancies, it has been suggested that lung cancer can be associated with other tumours on genetic basis (Haraguchi et al., 2007). In Poland, a common variant of CDKN2A with alanine to threonine substitution (A148T) was found to be common in melanoma, lung cancer and colorectal cancer patients (Debniak et al., 2006). In Sweden, association between lung, rectal, cervical, kidney and urinary bladder cancers was found (Li and Hemminki, 2003). An increased risk of any cancer (relative risk, $1.25 ; 95 \% \mathrm{CI}=1.05-1.50$ ) in the relatives of lung cancer patients as well as increased risk of breast cancer in female relatives of lung cancer patients was found by Gorlova et al., 2007.

In familial clustering of lung cancer, two main mechanisms could be proposed. The familial aggregation could be caused either by genetic factors or by heritability of lifestyle and passive smoking. The mapping of genetic susceptibility locus proves the presence of heritable genetic factor. Finally, epidemiologic analysis has demonstrated that heritability of smoking alone cannot explain the increased risk of lung cancer in the affected families (Bermejo and Hemminki, 2005). Indeed, synergistic influence of smoking and hereditary factors has been reported (Rachtan et al., 2008; Gorlova et al., 2007).
Although an expanding body of evidence substantiates the role of hereditary factors in the lung cancer development, the diagnostic criteria are not welldefined. It was suggested by Wood et al., 2000 that presence of at least 2 first-degree relatives with lung cancer in family, one of which is diagnosed before the age of 55, should reveal autosomal dominant hereditary lung cancer. However, these criteria were found to be too stringent by the same scientific group. There was an attempt to identify familial lung cancer by criteria that are analogous to Amsterdam criteria of hereditary nonpolyposis colorectal cancer. However, in a cohort of 1068 families identified by a proband having lung cancer, no family corresponded to all three criteria (Tomizawa et al., 1998).

Earlier onset is a well-known trait of inherited tumour. Occasionally, lung cancer has been reported in very young patients with family history of lung cancer but absence of Li-Fraumeni syndrome (Tajiri et al., 1999). However, it is evident from the meta-analysis that age limit does not add prognostic information in the risk estimates. In contrast, higher number of affected relatives is associated with a trend towards higher frequency of lung cancer: relative risk is estimated as $1.57(95 \% \mathrm{CI}=1.34-1.84)$ if 1 relative is affected and as $2.52(95 \% \mathrm{CI}=1.72-3.70)$ if at least 2 relatives are affected (Matakidou, Eisen and Houlston, 2005).

In summary, hereditary factors are likely to act in the development of lung cancer. The risk of tumour determined by genetic factors increase the risk caused by smoking and retain importance upon smoking cessation programs. The exact genetic defect comprising the hereditary risk of lung cancer is under investigation, but the most probable candidate region is 6q23-25. Hypothetically, other regions and genes may be involved. It is likely that several genetic syndromes of familial lung cancer exist, probably one of these involving lungs and other - specifically involving several organs. The familial lung cancer in the scientific viewpoint offers also unique possibility to study interaction between genetic and environmental factors as the most frequent cause of lung cancer is well-described.

As the search for the exact genetic marker for familial lung cancer is still under way, the diagnosis depends on clinical criteria. There is no sufficient evidence to add age as a diagnostic criterion of familial lung cancer. The published data suggest that the number of affected relatives is associated with the risk of lung cancer and thus can be used as a criterion in risk estimates. Hypothetically, these data could be obtained by population screening approach. However, there are almost no similar studies with the remarkable exception of population screening for hereditary and familial cancer in West Pomerania (Gronwald et al., 2006).

\section{AIM OF THE STUDY}

Here we present the first data about familial lung cancer in Latvia by clinical diagnostic criteria in population screening approach in order to study the occurrence and biological properties of this syndrome as well as 
the practical diagnostic possibilities. The data represent part of larger investigation, described in Materials and methods, aiming to analyse the role of population screening in the diagnostic pathway of hereditary cancer.

\section{MATERIALS AND METHODS}

The investigation was designed as population screening for hereditary cancer within the frames of the project "The development of hereditary cancer prophylaxis in Estonia and Latvia" co-financed by European Union Interreg IIIB Neighbourhood programme. The project was accepted by the Central Committee of Medical Ethics. The screening was carried out in the Valka district from 09/2005 to 06/2007, in collaboration with 22 family physicians. Family cancer histories in the form of questionnaires were voluntarily submitted by 18642 adults, representing $76.6 \%$ of the Valka district adult population. The questionnaire was designed to be simple. It contained questions if the blood relatives (siblings, children, parents and their siblings, grandparents) of the proband had had cancer, if yes - of what location, at what age, if the tumour has caused death, and at what age. Filled forms of family cancer history were sent to Hereditary Cancer Institute located at Paul Stradins Clinical University Hospital. The data about the presence and localisation of tumours in kinsmen, as well as about the age in the time of the diagnosis were analysed leading to clinical diagnoses of hereditary cancer syndromes by international criteria (Lynch et al., 2003; Gardovskis et al., 2005; Irmejs et al, 2007). If any hereditary cancer syndrome was suspected by the family cancer history, the corresponding persons were invited for consultation. During it, hereditary cancer syndrome entity was explained, written prophylactic recommendations were given and venous blood samples were proposed to take. Any person whose pedigree was consistent with any hereditary or familial cancer syndrome was considered and consulted as a proband giving him/her the widest opportunity to discuss the family cancer history with a specialist and to receive recommendations for follow-up if appropriate.

Additional data obtained during repeated consultations were applied in order to identify interrelated pedigrees. In this way, the possibility to include any person repeatedly in the analysis due to several kindred relationships was eliminated. Re-evaluation of the data characterising the affected persons was performed after detailed analysis of the blood relationships between different pedigrees. The frequency of lung cancer among blood relatives in the affected line was calculated. In order to characterise the cancer course within familial lung cancer syndromes, the data about tumour-affected persons were analysed, including the reported age of tumour diagnostics, tumour-related death and patient's survival. Descriptive statistical analysis was performed by CIA software. Within the frames of the presented study, familial lung cancer syndrome was diagnosed clinically by presence of lung cancer in at least 3 persons who were mutually firstdegree blood relatives. Suspected familial lung cancer syndrome was diagnosed, if 2 first-degree relatives had had lung cancer.

\section{RESULTS}

During the population screening, the first pedigrees with familial lung cancer in Latvia were identified. Several of these pedigrees demonstrated high number of the relevant tumours.

Familial lung cancer syndrome (FLC) was diagnosed in 13 probands (figure 1). Among them, there was oncologically healthy 44-year-old female, whose grandfather from paternal side as well as 3 brothers of father had had lung cancer. Another proband was 49year-old female, whose kindred demonstrated 5 cases of lung cancer. Familial lung cancer syndrome was diagnosed also in 55-year-old male who's father and 3 brothers of the father had had lung cancer. Fifty twoyear-old male presented family history of lung cancer in his mother, her father and brother; three other malignant tumours also were present in the kindred. The other FLC probands reported lung cancer in 3 mutually first-degree relatives. Suspected familial lung cancer syndrome was diagnosed in 93 probands. The population frequency of definitive and suspected familial lung cancer syndrome thus constituted $0.6 \%(95 \%$ confidence interval $(\mathrm{CI})=$ $0.5-0.7 \%$ ) of the studied Valka population. Nine of the probands diagnosed with FLC syndrome and

57 probands with sFLC syndrome were younger than 50 years (table 1). All probands were oncologically healthy themselves.

The 106 probands reported 232 blood relatives, affected by lung cancer. After re-evaluation as described in Materials and methods, 208 affected persons were recognised. Among them, there were 41 female (19.7\%; $95 \%$ CI $=14.9-25.6 \%)$ and 167 males $(80.3 \% ; 95 \%$ $\mathrm{CI}=74.4-85.1 \%)$. The lung cancer was diagnosed at the mean age of 57.9 years (interval, 18-90 years, standard deviation (SD) 12.3 years; 95\% CI $=55.9-59.9$ years). The affected persons whose exact death age was reported by the proband died at the mean age 60.3 years (interval, 13-90 years; SD 12.3 years; 95\% CI $=58.5-62.1$ years). The age of definite manifestation of the tumour was also evaluated including either data about the age of diagnostics if available or death age. The mean age of the definite manifestation of the tumour varied from 13 to 90 years, mean 58.8 years, SD 12.8 years, 95\% $\mathrm{CI}=57.0-60.6$ years. Only 3 of the affected persons were alive at the time of population screening. The average survival (see also figure 2) after the establishment of lung cancer diagnosis was 2.0 years (interval 0-59 years; SD 5.5 years; $95 \% \mathrm{CI}=1.1-2.9$ years). The first year lethality constituted 90/147 (61.2\%; 95\% CI = 53.2 $68.7 \%$ ) considering the persons about whom full data set is available.

The age of lung cancer diagnostics (figure 3) as well as the survival after the establishment of diagnosis showed differences between the pedigrees.

The number of affected persons and number of their blood relatives was determined for each kindred. The frequency of lung cancer was 40/157 (25.5\%; 95\% CI = 
$19.3-32.8 \%)$ in FLC pedigrees and 168/977 (17.2\%; $95 \%$ CI $=15.0-19.7 \%)$ in sFLC pedigrees. Further analysis was devoted to the frequency of lung cancer in FLC and sFLC pedigrees affected in a single generation or in 2 generations. The pedigrees were also classified into early-onset and late-onset groups by occurrence or absence of at least 1 cancer case at or before the age of 50 years. The respective data are shown in table 2 .

Among the early-onset FLC pedigrees, 4 of them were affected in 1 generation and 2 - in 2 generations. Among the late-onset FLC families, 1 of them was affected in 1 generation and 5 - in 2 generations. Analysing the early-onset sFLC pedigrees, 14 were affected in a single generation but 20 in 2 generations. Similarly, among late-onset sFLC families, 20 families were affected in a single generation and 39 - in 2 generations.

Possible association between familial lung cancer and occurrence of other malignancies was also studied. In general, no other tumours were found in 54 pedigrees. Among the other families, 11 cases of endometrial cancer, 10 cases of breast cancer, 8 cases of colorectal cancer, 8 cases of hematologic malignancies, 6 cases of stomach cancer, 1 case of duodenal malignancy, 4 cases of ovarian cancer, 3 cases of pancreatic cancer, 2 cases of renal cancer, 2 cases of head and neck cancer were observed. In 5 persons, bones were affected, invariably spine. Liver was affected in 3 cases, brain - in 1 case. In 5 cases the location of cancer was unknown for the proband. The rate of lung cancer was 126/654 (19.3\%; $95 \% \mathrm{CI}=16.4-22.5 \%)$ in the families without history of other tumours and 106/594 (17.8\%; 95\% CI $=15.0-$ $21.0 \%$ ) in families with mixed cancer history.

\section{DISCUSSION}

The published data suggest the existence of the hereditary background in the development in lung cancer. The epidemiological evidence of familial clustering is substantiated by mathematical models that help to evaluate the input of genetic and behavioural factors. The final proof will be brought by genetic research moving towards identification of genes and mutations responsible for lung cancer susceptibility.

In the result of population screening we have identified a group of familial lung cancer syndrome including 13 pedigrees of definitive and 93 - of suspected familial lung cancer syndrome with population frequency $0.6 \%$ $(95 \% \mathrm{CI}=0.5-0.7 \%)$. The frequency of lung cancer cases among blood relatives in this group is high reaching $25.5 \%(95 \% \mathrm{CI}=19.3-32.8 \%)$ in FLC and $17.2 \%(95 \%$ $\mathrm{CI}=15.0-19.7 \%)$ in sFLC. This exceeds significantly the EU cumulative risk of lung cancer (age 0-74 years) estimated as $6.5 \%$ in men and $1.6 \%$ in women (Boyle and Ferlay, 2005) taking into account the fact that lung cancer incidence in Latvia is close to the EU average (Kaiser and Gommer, 2007). Thus, our criteria are useful in order to identify high-risk group of practical size. It should be noted that at the present phase of medical science development the familial lung cancer concept is still under research. However, within the frames of our survey it has already shown its practical merit.
The identified probands were oncologically healthy. However, this cannot be interpreted as risk-lowering factor as, firstly, most probands are young; secondly, lung cancer once already developed would rapidly eliminate the affected person from screening. The last assumption is based on the survival data in our group showing firstyear lethality $61.2 \%(95 \%$ CI $=53.2-68.7 \%)$. Only 3 affected people were alive at the time of population screening.

The age of cancer onset varied widely. The youngest case in our group died at the age 13 years. Although this would be an unusually early onset of lung cancer in general, it is in accordance with literature data (Tajiri et al., 1999). Further investigation of such cases would be necessary; however, it was beyond the scope of population screening. However, the mean age of cancer diagnostics was 57.6 years $(95 \% \mathrm{CI}=55.7-59.5$ years $)$ and of definite tumour manifestation -58.8 years $(95 \%$ $\mathrm{CI}=57.0-60.6 \%)$. Thus, very early onset is not a rule. Adding the age of tumour onset to the analysis, no significant differences in cancer frequency were observed. Thus, our findings are in agreement with the published evidence that familial cancer has a trend towards early occurrence but the age of cancer diagnostics still is not ready for implementation as a strict diagnostic criterion (Matakidou, Eisen and Houlston, 2005).

We have detected trend towards higher rate of lung cancer in definitive familial lung cancer families $(95 \% \mathrm{CI}=$ $19.3-32.8 \%)$ than in suspected cases $(95 \% \mathrm{CI}=15.0$ $19.7 \%)$. This is in agreement with the published data suggesting increased frequency with higher number of affected relatives. Although the trend did not reach $95 \%$ probability level, it initiated the search for additional factors that might help to evaluate the risk more exactly. The number of affected generations was found to be important. The frequency of lung cancer was significantly lower in sFLC families affected in single generation (95\% CI $=12.3-19.1 \%)$ in comparison to the FLC group $(95 \% \mathrm{CI}=19.3-32.8 \%)$. Complexity was added by the observation that FLC families that are affected in single generation show trend to even higher cancer frequency than FLC families affected in 2 generations. Further analysis in larger group would be necessary. If the trend would be confirmed, complex genetic background could be suspected. This would be in accordance with the medical literature (Li and Hemminki, 2005; Sellers et al., 1990). Genetic heterogeneity could also be further suspected on the basis of our data, namely, the clinical differences between families.

In our group, similarly to the published findings (Nitadori et al., 2006), the frequency of lung cancer in the familial lung cancer families was not influenced by general family cancer history.

The presented study was devoted to the analysis of family cancer history. It was limited by several factors. First, the influence of environmental etiological factors was not considered at the present stage. The interplay between smoking and positive family history has been checked by Bermejo and Hemminki, 2005 providing evidence that familial aggregation of lung cancer cases cannot 
be explained by shared etiologic factors or heritability of lifestyle. The role of hereditary factors and smoking in lung cancerogenesis is not mutually exclusive as synergistic influence of smoking and hereditary factors has been reported (Rachtan et al., 2008; Gorlova et al., 2007). Second, the family history was reported by proband only. The published studies describe sufficient accuracy of reporting a severe disease in a close relative by non-medical person (Love et al., 1985). Besides that, the ancient medical documentation in Latvia also can be subjected to various bias.

The results of Valka population screening should be considered as a pilot study. In the whole Latvia, distinctive results could be expected due to different ethnic composition, levels of environmental factors or other factors. However, the population screening has demonstrated the possibility to identify risk persons by completing an easy questionnaire. While the scientists in the whole world are still searching for the underlying genetic defect and thus diagnostics of mutations is not accessible, there is no possibility to consider the completeness of such approach.

As shown by our results, the population screening identifies the persons-at-risk at sufficiently early age to provide prophylaxis programs. The literature data mostly suggest development of non-small cell lung cancer in familial lung cancer families. Thus, the population screening as a cancer prevention tool and the biology of familial lung cancer fits together in order to provide the best assistance for the risk group. Both FLC and sFLC should be included in the risk group and undergo regular surveillance for timely diagnostics and surgery. Additionally, the identified group could be a target of educational efforts aiming at smoking cessation. It could be reasonable to propose that these people after receiving adequate information may develop high motivation for healthy life style.

The familial lung cancer concept thus is promising in the practical field as well as in further scientific studies including the final solution of genetic workup.

\section{CONCLUSIONS}

1. The population screening has brought the first evidence of familial lung cancer in Latvia with the frequency $0.6 \%$ of population.

2. The diagnostic criteria based on the presence of at least 2 lung cancer cases among blood relatives allow identifying oncologically healthy persons from high-risk families at early age. Thus, population screening is an effective tool in identification of risk group and initiation of protective measures.

3. Familial lung cancer syndrome can be diagnosed by use of simple questionnaire that was applied in the presented study.

4. Number of lung cancer cases in the pedigree is the most important diagnostic criterion allowing discriminating between groups of pedigrees with different although high frequencies of lung cancer. The diagnostic role of early cancer development and higher number of affected generations should be further investigated.

\section{ACKNOWLEDGEMENTS}

The pilot project of the population screening was carried out within the frames of the project "The development of hereditary cancer prophylaxis in Estonia and Latvia" co-financed by European Union Interreg IIIB Neighbourhood program and including participation of the following Valka district family physicians: Maruta Bindre, Lilita Ezerina, Juris Ezerins, Elvira Freiberga, Alla Grinberga, Sanita Jansone, Alda Karklina, Maija Klavina, Ritma Klavina, Marianna Kire, Valdis Kiris, Zane Lukina, Inga Natra, Maris Natra, Liga Putrina, Olga Ribkina, Anna Sakare, Ilona Uzbeka, Inese Verselo, Sniedze Viksna, Maija Zalite, Liga Ziemele.

\section{Conflict of interest: None}

\section{REFERENCES}

1. Ambrosone CB, Rao U, Michalek AM, Cummings KM, Mettlin CJ. Lung cancer histologic types and family history of cancer. Analysis of histologic subtypes of 872 patients with primary lung cancer // Cancer, 1993; 72(4):1192 - 1198

2. Bailey-Wilson JE, Amos CI, Pinney SM, Petersen GM, de Andrade M, Wiest JS, Fain P, Schwartz AG, Ypu M, Franklin W, Klein C, Gazdar A, Rothschild H, Mandal D, Coons T, Slusser J, Lee J, Gaba C, Kupert E, Perez A, Zhou X, Zeng D, Liu Q, Zhang Q Seminara D, Minna J, Anderson MW. A Major lung cancer susceptibility locus maps to chromosome 6q23-35 // Am J Hum Genet, 2004; 75(3):460 474

3. Bell DW, Gore I, Okimoto RA, Godin-Heymann N, Sordella R, Mulloy R, Sharma SV, Brannigan BW, Mohapatra G, Settleman J, Haber DA. Inherited susceptibility to lung cancer may be associated with the T790M drug resistance mutation in EGFR // Nat Genet, 2005; 37(12):1315 - 1316

4. Bermejo JL, Hemminki K. Familial lung cancer and aggregation of smoking habits: a simulation of the effect of shared environmental factors on the familial risk of cancer // Cancer Epidemiol Biomarkers Prev, 2005; 14(7):1738 - 1740

5. Boyle P. and Ferlay J. Cancer incidence and mortality in Europe, 2004 // Annals of Oncology, 2005; 16:481 - 488

6. Debniak T, Scott RJ, Huzarski T, Byrski T, Rozmiarek A, Debniak B, Górski B, Cybulski C, Medrek K, Mierzejevski M, Masojc B, Matyjasik J, Złowocka E, Teodorczyk U, Lener M, Klujszo-Grabowska E, Nej-Wołosiak K, Jaworowska E, Oszutowska D, Szymańska A, Szymańska J, Castaneda J, van de Wetering T, Suchy J, Kurzawski G, Oszurek O, Narod S, Lubinski J. CDKN2A common variant and multiorgan cancer risk - a population-based study // Int J Cancer, 2006, 118(12):3180 - 3182

7. Ganti AK, Loberiza FR Jr, Kessinger A. Association of positive family history with survival of patients 
with lung cancer // Lung Cancer, 2009; 63(1):136 139

8. Gardovskis A, Irmejs A, Miklasevics E, Borosenko V, Bitina M, Melbarde-Gorkusa I, Vanags A, Kurzawski G, Suchy J, Gorski B, Gardovskis J. Clinical, molecular and geographical features of hereditary breast/ovarian cancer in Latvia // Hereditary Cancer in Clinical Practice, 2005; 3(2):71 - 76

9. Gorlova OY, Weng SF, Zhang Y, Amos CI, Spitz MR. Aggregation of cancer among relatives of neversmoking lung cancer patients // Int J Cancer, 2007; $121(1): 111-118$

10. Gronwald J, Raczynski A, Tarhoni M, Blachowski M, Huzarski T, Byrski T, Toloczko-Grabarek A, Debniak T, Cybulski C, Huzarska J, Oszurek O, Lubinski J. Population screening for cancer family syndromes in the West Pomeranian region of Poland // Hereditary Cancer in Clinical Practice, 2006; 4(1):56

11. Haraguchi S, Koizumi K, Hioki M, Hisayoshi T, Hirata T, Shimizu K. Hereditary factors in multiple primary malignancies associated with lung cancer // Surg Today, 2007; 37(5):375 - 378

12. Hemminki K, Li X. Familial risk for lung cancer by histology and age of onset: evidence for recessive inheritance // Exp Lung Res 2005; 31(2):205 - 15

13. Irmejs A, Borosenko V, Melbarde-Gorkusa I, Gardovskis A, Bitina M, Kurzawski G, Suchy J, Gorski B, Gardovskis J. Nationwide study of clinical and molecular features of hereditary non-polyposis colorectal cancer (HNPCC) in Latvia // Anticanc Res, 2007; 27:653-658

14. Jonsson S, Thorsteinsdottir U, Gudbjartsson DF, Jonsson HH, Kristjansson K, Arnason S, Gudnason $\mathrm{V}$, Isaksson HJ, Hallgrimsson J, Gulcher JR, Amundadottir LT, Kong A, Stefansson K. Familial risk of lung carcinoma in the Icelandic population // JAMA, 2004; 292:2977 - 2983

15. Kaiser S, Gommer AM. Lung cancer. In: Estimates of the incidence and prevalence of, and mortality from 27 cancers for all countries in the world in 2002 provided by the Descriptive Epidemiology Group (DEP) of IARC. Globocan, 2007

16. Li X, Hemminki K. Familial and second lung cancers: a nation-wide epidemiologic study from Sweden // Lung Cancer, 2003; 39(3):255 - 263

17. Liu P, Vikis HG, Wang D, Lu Y, Wang Y, Schwartz AG, Pinney SM, Yang $\mathrm{P}$, de Andrade M, Petersen GM, Wiest JS, Fain PR, Gazdar A, Gaba C, Rothschild H, Mandal D, Coons T, Lee J, Kupert E, Seminara D, Minna J, Bailey-Wilson JE, Wu X, Spitz MR, Eisen T, Houlston RS, Amos CI, Anderson MW, You M. Familial aggregation of common sequence variants on 15q24-25.1 in lung cancer // J Natl Cancer Inst 2008; 1000(18):1326 - 1330

18. Love RR, Evans AM, Josten DM. The accuracy of patient reports of family history of cancer // J Chronic Dis, 1985; 38:289-93

19. Lynch HT, Riley BR, Weisman S, Coronel SM, Kinarsky Y, Lynch JF, Shaw TG, Rubinstein WS
Hereditary nonpolyposis colorectal carcinoma (HNPCC) and HNPCC - like families: problems in diagnosis, surveillance and management // Cancer, 2004; 100(1):53-64

20. Matakidou A, Eisen T, Bridle H, O'Brien M, Mutch R, Houlston RS. Case-control study of familial lung cancer risks in UK women // Int J Cancer, 2005; $116(3): 445-450$

21. Matakidou A, Eisen T, Houlston RS. Systematic review of the relationship between family history and lung cancer risk // British Journal of Cancer, 2005; 93:825 - 833

22. Nitadori J, Inoue M, Iwasaki M, Otani T, Sasazuki S, Nagai K, Tsugane S. Association between lung cancer incidence and family history of lung cancer: Data from a large-scale, population-based cohort study, the JPHC study // Chest, 2006; 130(4):968 975

23. Parkin DM, Bray F, Ferlay J, Pisani P. Global cancer statistics, 2002 // CA Cancer J Clin, 2005; 66:74 108

24. Rachtan J, Sokolowski A, Niepsuj S, Zemła B, Zwierko M. Familial lung cancer risk among women in Poland // Lung Cancer, 2009; 65(2):138 - 143

25. Schwartz AG, Ruckdeschel JC. Familial lung cancer: genetic susceptibility and relationship to chronic obstructive pulmonary disease // Am J Respir Crit Care Med, 2006; 173(1):16 - 22

26. Sellers TA, Bailey-Wilson JE, Elston RC, Wilson AF, Elston GZ, Ooi WL, Rothschild H. Evidence for mendelian inheritance in the pathogenesis of lung cancer // J Natl Cancer Inst, 1990; 82(15):1272 1279

27. Sellers TA, Elston RC, Atwood LD, Rothschild H. Lung cancer histologic type and family history of cancer // Cancer, 1992; 69(1):86 - 91

28. Tajiri T, Suita S, Shono K, Kubota M, Taguchi T, Yamanouchi K, Noguchi S, Tsuneyoshi M. Lung cancer in a child with a substantial family history of cancer // Eur J Pediatr Surg, 1999; 9(6):409 - 412

29. Tokuhata GK, Lilienfeld AM. Familial aggregation of lung cancer in humans // J Natl Cancer Inst 1963; 30:289 - 312

30. Tomizawa Y, Adachi J, Kohno T, Yamaguchi N, Saito $\mathrm{R}$, Yokota J. Identification and characterization of families with aggregation of lung cancer // Japanese Journal of Clinical Oncology, 1998; 28(3):192 195

31. Wood ME, Kelly K, Mullineaux LG, Bunn PA Jr. The inherited nature of lung cancer: a pilot study // Lung Cancer, 2000; 30(2):135 - 44

32. Wu AH, Fontham ET, Reynolds P, Greenberg RS, Buffler P, Liff J, Boyd P, Correa P. Family history of cancer and risk of lung cancer among lifetime nonsmoking women in the United States // Am J Epidemiol, 1996; 143(6):535 - 542

33. You $M$, Wang D, Liu P, Vikis H, James M, Lu Y, Wang Y, Wang M, Chen Q, Jia D, Liu Y, Wen W, Yang P, Sun Z, Pinney SM, Zheng W, Shu XO, Long J, Gao YT, Xiang YB, Chow WH, Rothman N, Petersen 
GM, de Andrade M, Wu Y, Cunningham JM, Wiest JS, Fain PR, Schwartz AG, Girard L, Gazdar A, Gaba C, Rothschild H, Mandal D, Coons T, Lee J, Kupert E, Seminara D, Minna J, Bailey-Wilson JE, Amos $\mathrm{CI}$, Anderson MW. Fine mapping of chromosome 6q23-25 region in familial lung cancer families reveals RGS17 as a likely candidate gene // Clin Cancer Res 2009; 15(8):2666 - 2674

\section{Address:}

Andrejs Vanags,

Hereditary Cancer Institute,

Riga Stradins University,

Dzirciema Street 16, LV 1007, Riga, Latvia,

E-mail: vanags314@inbox.lv

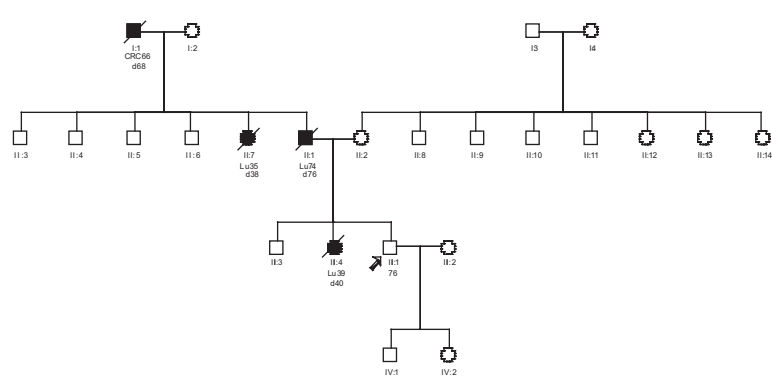

Fig. 1. Pedigree showing familial lung cancer

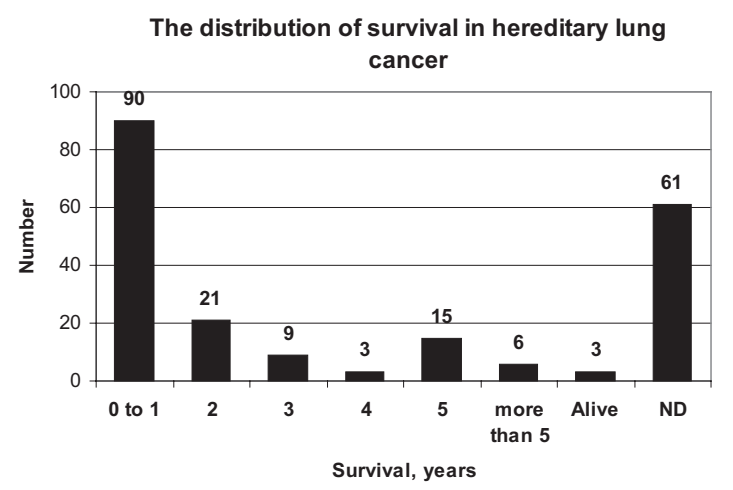

Fig. 2. Survival of lung cancer patients from familial lung cancer families. Abbreviation in figure: ND, no data available
Table 1. Age distribution of probands with familial lung cancer syndromes

\begin{tabular}{|c|c|c|c|c|c|c|c|c|}
\hline Diag- & Total & \multicolumn{7}{|c|}{ Age, years } \\
\cline { 3 - 9 } nosis & $\begin{array}{c}\text { num- } \\
\text { ber }\end{array}$ & $18-29$ & $30-39$ & $40-49$ & $50-59$ & $60-69$ & $70-79$ & $\geq 80$ \\
\hline FLC & 13 & 4 & 1 & 4 & 2 & 1 & 1 & 0 \\
\hline sFLC & 93 & 15 & 18 & 24 & 13 & 13 & 5 & 5 \\
\hline
\end{tabular}

Abbreviations in table: FLC, familial lung cancer; sFLC susp., suspected familial lung cancer; $\geq$, greater than or equal to.

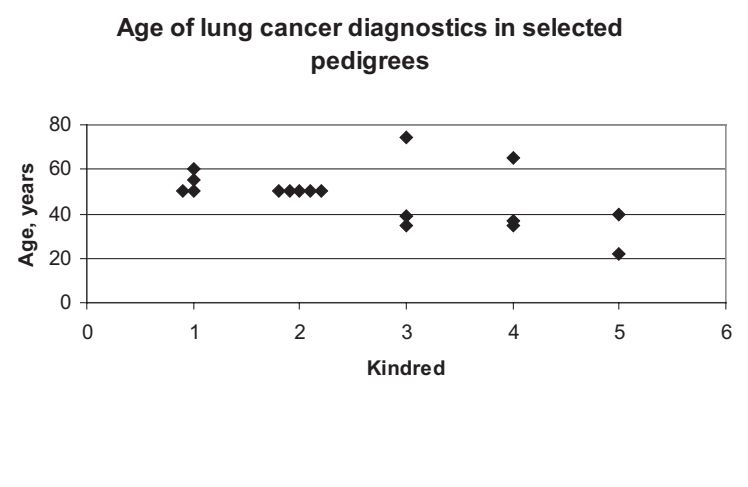

Fig. 3. Age of lung cancer diagnostics in the affected persons from definitive and suspected familial lung cancer pedigrees 